\title{
Effect of arginine pre-treatment on nickel accumulation and alleviation of the oxidative stress in Hyoscyamus niger
}

\author{
F. Nasibi*, T. Heidari, Z. Asrar, H. Mansoori \\ Biology Department, Faculty of Sciences, Shahid Bahonar University of Kerman. Iran. 'Corresponding author: nasibi2002@yahoo. \\ com
}

\begin{abstract}
Nickel is essential for many plant species to complete their life cycle but higher concentrations of this metal are toxic and may severely interfere with many physiological and biochemical processes of plants. In recent researches, either sodium nitroprusside (as nitric oxide donor) or exogenous polyamines were used to counteract the effect of heavy metal stress. In this research hyoscyamus plants were pre-treated with 10 and $20 \mu \mathrm{M} A r g$ (as a precursor of $\mathrm{NO}$ or polyamines) and then plants were treated with 50 and $100 \mu \mathrm{M} \mathrm{Ni}$. Elevated hydrogen peroxide content and lipoxygenase (LOX) activity showed that $\mathrm{Ni}$ induced oxidative damages. Antioxidant enzyme activity also increased in those plants which were under Ni stress. In plants, which were pretreated with Arg, the concentration of $\mathrm{Ni}$ increased in shoot, while the $\mathrm{H}_{2} \mathrm{O}_{2}$ content and the activity of LOX, catalase (CAT), guiacol peroxidase (GPX) and ascorbate peroxidase (APX) enzymes decreased. It is shown for the first time that pre-treatment of hyoscyamus plant with Arg increased plant capability to accumulate $\mathrm{Ni}$ in its aboveground organs by 1.5-2 times and reduced its toxic effects indicated by measurement of oxidative parameters. It might be true because Arginine induced alleviation of Ni toxicity and accelerated transport by chelating of Ni in plants directly or through production of polyamines.
\end{abstract}

Keywords: Antioxidant enzymes, heavy metals, hydrogen peroxide, polyamines

\section{Introduction:}

Heavy metal pollution is a worldwide problem with serious environmental consequences. Amongst heavy metals, nickel $(\mathrm{Ni})$ is an essential micronutrient for plant growth. It is a constituent of the enzyme urease and in small quantities is essential for many plant species to complete their life cycle (Seregin and Kozhevnikova, 2006) but higher concentrations of this metal are toxic and may severely interfere with many physiological and biochemical processes of plants (Seregin and Kozhevnikova, 2006). If the plants taken up larger amounts of nickel, the common symptoms of $\mathrm{Ni}$ toxicity are chlorosis, weak plant growth, yield depression and may even be accompanied by reduced nutrient uptake and disorders in plant metabolism (Yang, 1996). Ni excess in the environment also decreases chlorophyll content and growth in metal 
sensitive plants (Boominathan and Doran, 2002). Many abiotic environmental stresses including salinity, drought stress, temperature extremes, and metal toxicity disrupt the redox homeostasis of cells and exert a wide range of adverse effects on plant growth and metabolism (Sharma and Dubey, 2007; Nasibi and Kalantari, 2009). These stressful conditions induce overproduction of reactive oxygen species (ROS). ROS are known to damage cellular membranes by inducing lipid peroxidation and can damage DNA, proteins and chlorophyll (Mittova et al., 2000). The lifetime of active oxygen species within the cellular environment is determined by the antioxidant system, which provides crucial protection against oxidative damage. The antioxidative system comprises numerous enzymes such as super oxide dismutase (SOD), CAT, APX and GPX and non-enzymatic antioxidants with low molecular weight including ascorbic acid and reduced glutathione (GSH) (Sharma and Dubey, 2007). It has been suggested that Ni-induced phytotoxicity, is associated with $\mathrm{Ni}$-stimulated oxidative stress in certain plant species (Boominathan and Doran, 2002). Since Ni is a redox-inactive metal, it cannot directly generate ROS. Membrane peroxidation, however, has been observed in various plants subject to $\mathrm{Ni}$ toxicity (Boominathan and Doran, 2002; Gajewska and Sklodowska, 2005). In addition, enzymes related to antioxidant defense systems have also been shown to be stimulated in response to $\mathrm{Ni}$-induced oxidative stress (Gajewska and Sklodowska, 2005).

In previse studies, the specific role of some amino acids in the plant responses to abiotic stress have been reported. For example it has been reported that accumulation of proline caused prevention of metal-induced lipid peroxidation (Mehta and Gaur 1999) or complex of histidine (His) with $\mathrm{Ni}$, caused accumulation of $\mathrm{Ni}$ in shoots of Hyper accumulator plants (Shanti et al. 2006). In addition, upon exposure to metals, plants often synthesize a set of diverse metabolites that accumulate to concentrations in the milimolar range, particularly specific amino acids, such as proline and histidine, peptides such as glutathione and phytochelatins (PC), and the amines spermine, spermidine, putrescine, nicotianamine, and mugineic acids (Sharma and Dietz, 2006). L-arginine is one of the most functionally diverse amino acids in living cells. In addition to serving as a constituent of proteins, arginine is a precursor for biosynthesis of polyamines, Agmatine and proline as well as the cell signaling molecules glutamine and nitric oxide (Liu et al. 2006). In previous research, sodium nitroprruside (SNP) as a NO donor or exogenous polyamines was used to counteract the effect of heavy metal (Wang, 2007; Hsu and Kao, 2004; Tewari et al., 2008). However not any data are available on the effect of exogenous arginine as a precursor of these compounds in the possible anti oxidative responses of plants against Ni stress. The aim of this work is designed to study the effects of arginine pre-treatment on alleviation of oxidative damages induced by $\mathrm{Ni}$ stress. We also examined the effects of Arg on Ni accumulation in Hyoscyamus plants. Comparing these responses can be useful for understanding the physiological and biochemical mechanisms of Arginine in those plants which have to cope with heavy metal stress.

\section{Materials and Methods}

\subsection{Plant material}

Henban plants (Hyoscyamus niger) were grown from seeds in plastic pots contains sand and compost until the seeds were germinated. The seedlings were irrigated with water once a day and half-strength Hogland solution once a week. After four weeks of growth, the seedlings were transferred to bottles containing Hoagland solution aerated with air pump and were pretreated with 10 or $20 \mu \mathrm{M}$ Arginine (Arg was added to nutrient solution). These concentrations of Arg were optimized in preliminary experiment. After $24 \mathrm{~h}$, plants were subjected to Ni stress. For this purpose 3 seedlings were placed in aerated bottle containing distilled water served as a control and 50 or $100 \mu \mathrm{M}$ Ni solutions. After $24 \mathrm{~h}$ of Ni stress, the shoot and root of plants were harvested and 
immediately frozen in liquid nitrogen and stored at $-80{ }^{\circ} \mathrm{C}$ for future analysis.

\subsection{Chlorophyll content}

The amount of photosynthetic pigment, (chlorophyll a, $\mathrm{b}$, total and carotenoids), were determined according to the method of Lichtenthaler et al. (1987). The pigment extract was measured against a blank of $80 \%(\mathrm{~V} / \mathrm{V})$ acetone at wavelengths of 646.8 and $663.2 \mathrm{~nm}$ for chlorophyll assays.

\subsection{Hydrogen peroxide content}

Hydrogen peroxide levels were determined according to Alexieva et al. (2001). Fresh leaves $(0.5 \mathrm{~g})$ were homogenized in ice bath with $5 \mathrm{ml} 0.1 \%(\mathrm{w} / \mathrm{v})$ trichloro acetic acid (TCA). The homogenate was centrifuged at $12,000 \times \mathrm{g}$ for $15 \mathrm{~min}$ and $0.5 \mathrm{ml}$ of the supernatant was added to $0.5 \mathrm{ml}$ of $10 \mathrm{mM}$ potassium phosphate buffer (pH 7.0) and $1 \mathrm{ml}$ of $1 \mathrm{M} \mathrm{KI}$. The reaction was carried out for $1 \mathrm{~h}$ in darkness and absorbance was measured at $390 \mathrm{~nm}$. The amount of hydrogen peroxide was calculated using a standard curve prepared with known concentration of $\mathrm{H}_{2} \mathrm{O}_{2}$.

\subsection{Proline determination}

Determination of free proline content performed according to Bates et al. (1973).

\subsection{Enzyme extraction and activity determination}

Five hundred mg leaves were homogenized in an ice cold mortar using $50 \mathrm{mM}$ potassium phosphate buffer $(\mathrm{pH}=7.0)$ containing $1 \mathrm{mM}$ EDTA, $1 \%(\mathrm{w} / \mathrm{v})$ soluble PVP, and $1 \mathrm{mM}$ PMSF. After centrifugation $(20000 \times$ g, $20 \mathrm{~min}$ ) the supernatant was used for determination of LOX, CAT, GPX and APX activities.

\subsection{Lipoxygenase activity}

The LOX activity was estimated according to the method of Dodere et al. (1992). For measurement of LOX activity $50 \mu 1$ of enzyme extraction was added absorbance was recorded at $234 \mathrm{~nm}$ and the activity was expressed as unit per $\mathrm{mg}$ protein in the leaves (extinction coefficient of $25000 \mathrm{M}^{-1} \mathrm{~cm}^{-1}$ )

\subsection{Catalase activity (EC 1.11.1.6)}

The CAT activity was assayed by measuring the initial rate of $\mathrm{H}_{2} \mathrm{O}_{2}$ disappearance at $240 \mathrm{~nm}$ using the extinction coefficient of $40 \mathrm{mM}^{-1} \mathrm{~cm}^{-1}$ for $\mathrm{H}_{2} \mathrm{O}_{2}$ (Velikova et al., 2000)

\subsection{Guaiacol peroxidase (EC1.11.1.7)}

The GPX activity was determined using the method of Plewa et al. (1999) following the formation of tetraguaiacol by measuring the absorbance at $470 \mathrm{~nm}$ and using an extinction coefficient of $25.5 \mathrm{mM}^{-1} \mathrm{~cm}^{-1}$.

\subsection{Ascorbate peroxidase (EC 1.11.1.11)}

The APX activity was determined spectrophotometrically according to the oxidation of ASA. The reaction solution contained $50 \mathrm{mM}$ potassium phosphate buffer $(\mathrm{pH}=7.0), 0.5 \mathrm{mM}$ ascorbate, $0.1 \mathrm{mM} \mathrm{H}_{2} \mathrm{O}_{2}$ and $150 \mu 1$ enzyme extract. $\mathrm{H}_{2} \mathrm{O}_{2}$-dependent oxidation of ASA was followed by measuring the decrease in absorbance within $1 \mathrm{~min}$ at 290 (extinction coefficient of $2.8 \mathrm{mM}^{-1} \mathrm{~cm}^{-1}$ ) (Nakano \& Asada, 1981)

\subsection{Total soluble proteins}

Protein content was determined according to the method of Bradford (1976) using Bovine serum albumin as standard.

\subsection{Determination of Ni concentration in leaves of plants}

Nickel content in leaves was determined by atomic absorption spectrometry (SpektrAA 300, Varian, Mulgrave, Australia) following wet digestion of oven dried tissue in $\mathrm{HNO}_{3}$ solution at $140{ }^{\circ} \mathrm{C}$. 


\subsection{Statistical analysis}

The experiments were performed in a randomized order. Data were expressed as mean of three replicates with standard error. Stwatistic assays were carried out by one-way ANOVA using Duncan test to evaluate whether the means were significantly different, taking $p<0.05$ as significant.

\section{Results}

\subsection{Chlorophyll content}

Results showed that chlorophyll a and total chlorophyll decreased in plants, which were under $100 \mu \mathrm{M}$ nickel while Ni stress had no effects on chlorophyll b content. Arginine pre-treatment $(10 \mu \mathrm{M})$ increased the chlorophyll content in Ni stressed plants (Table1).

Table 1: Effect of Arg pre-treatments $(10$ and $20 \mu \mathrm{M})$ on photosynthetic pigments in Hyoscyamus niger leaves under control and Ni stress $(50$ and $100 \mu \mathrm{M})$ condition. Data are means \pm SE of three replicates. The significant of different between treatments was determined by one-way ANOVA taking $p<0.05$ as significant.

\begin{tabular}{|c|c|c|c|}
\hline Treatments & $\begin{array}{l}\text { Chlorophyll a } \\
\qquad\left(\mathrm{mg} \mathrm{gfw}^{-1}\right)\end{array}$ & $\begin{array}{c}\text { Chlorophyll } b \\
\left(\mathrm{mg} \mathrm{gfw}^{-1}\right)\end{array}$ & $\begin{array}{c}\text { Total Chlorophyll } \\
\left(\mathrm{mg} \mathrm{gfw}^{-1}\right)\end{array}$ \\
\hline Control & 88.5021 abcd & $40.2071 \mathrm{~b}$ & $128.7092 \mathrm{bcd}$ \\
\hline $10 \mu \mathrm{M}$ Arg & $96.12797 \mathrm{abc}$ & $32.06897 \mathrm{bc}$ & $128.1969 \mathrm{bcd}$ \\
\hline $20 \mu \mathrm{M}$ Arg & $106.019 \mathrm{ab}$ & $39.4051 \mathrm{~b}$ & $145.4241 \mathrm{abc}$ \\
\hline $50 \mu \mathrm{M} \mathrm{Ni}$ & 80.33937 bcd & $39.1971 \mathrm{~b}$ & 119.5365 cde \\
\hline $50 \mu \mathrm{M} N \mathrm{~N}+10 \mu \mathrm{MArg}$ & $111.0541 \mathrm{a}$ & $54.7634 \mathrm{a}$ & $165.8175 \mathrm{abc}$ \\
\hline $50 \mu \mathrm{M} N \mathrm{Ni}+20 \mu \mathrm{MArg}$ & $98.74033 \mathrm{ab}$ & $40.97307 \mathrm{~b}$ & $139.7134 \mathrm{abc}$ \\
\hline $100 \mu \mathrm{M} \mathrm{Ni}$ & $67.1349 \mathrm{~d}$ & $30.9924 \mathrm{bc}$ & $98.1273 \mathrm{de}$ \\
\hline $100 \mu \mathrm{M} \mathrm{Ni}+10 \mu \mathrm{MArg}$ & $108.9297 \mathrm{a}$ & $51.27473 \mathrm{a}$ & $160.2045 \mathrm{abc}$ \\
\hline $100 \mu \mathrm{M} \mathrm{Ni}+20 \mu \mathrm{MArg}$ & $69.98387 \mathrm{~cd}$ & $25.9962 \mathrm{c}$ & $95.98007 \mathrm{e}$ \\
\hline
\end{tabular}




\section{2. $\mathrm{H}_{2} \mathrm{O}_{2}$ accumulation and LOX activity}

$\mathrm{Ni}$ stress caused an increase in $\mathrm{H}_{2} \mathrm{O}_{2}$ accumulation in leaves of plants (Figure 1-A). Arg pre-treatment had no significant effect in decreasing of $\mathrm{H}_{2} \mathrm{O}_{2}$ in control condition. However, in those plants which were under Ni stress, 10 and $20 \mu \mathrm{M}$ Arg pre-treatments decreased the amount of hydrogen peroxide. Lipoxygenase is an oxidative enzyme that induces lipid peroxidation. The activity of this enzyme increased significantly in Ni stressed plants (Figure 1-B). Arg pre-treatment decreased the activity of this enzyme in those plants which were under Ni stress. However pre-treatment of plants with $10 \mu \mathrm{M}$ Arg was more effective when compared with those plants which were pretreated with $20 \mu \mathrm{M}$ Arg.

\subsection{Proline content}

The amounts of proline increased significantly under Ni stress. Treatment of plants with Arg decreased the proline content in control and $100 \mu \mathrm{M} \mathrm{Ni}$ stressed plants while Arg pre-treatment had no effects on proline content of plants which were under $50 \mu \mathrm{M} \mathrm{Ni}$ stress (Figure 2).

\subsection{Antioxidant enzyme activities}

The effect of Ni stress on CAT, GPX and APX in Hyoscyamus leaves, either with or without Arg pretreatment was assayed. As it is shown in (Figure 3-A, $\mathrm{B}$ and C) the activity of CAT, GPX and APX were higher in stressed plants than those of the control groups, which may be a reflection of the oxidative stress induced by Ni stress. Pre-treatment of plants with Arg decreased the activity of CAT and APX enzymes in control, and stress conditions however Arg pre-treatment decreased the GPX in $100 \mu \mathrm{M}$ Ni stress and had no effects on GPX in control and $50 \mu \mathrm{M} \mathrm{Ni}$ stress condition.

\subsection{Ni concentration in leaves of plants}

Determination of $\mathrm{Ni}$ content by atomic absorption showed that the Ni concentration increased in leaves of plants under Ni stress and the Arg pre-treatment increased the Ni content in stressed plants.

\section{Discussion}

Nickel is toxic at high plant-available concentrations and can have detrimental effects on plant growth and metabolism (Seregin and Kozhevnikova, 2006). Our results showed that Ni toxicity in hyoscyamus plant is strongly correlated with higher oxidative damage in shoot, as demonstrated by decrease in chlorophyll content, elevation of hydrogen peroxide and LOX activity, which induced lipid peroxidation. Uptake of $\mathrm{Ni}$ increased with increasing $\mathrm{Ni}$ concentration in the growth medium as revealed by the shoot Ni content. The increase in hydrogen peroxide content and LOX activity with increasing $\mathrm{Ni}$ levels suggests that $\mathrm{Ni}$ induces oxidative stress in growing hoscyamus plants. The elevated CAT, GPX and APX activities in shoot treated with high Ni concentration may be a defense response to Ni toxicity. Enhanced the activity of this enzymes in stress condition are available for $\mathrm{H}_{2} \mathrm{O}_{2}$ scavenging, but the enhanced activity of these enzymes is apparently not sufficient to maintain a cellular redox balance under $\mathrm{Ni}$ toxicity. This finding is consistent with reports on elevated root and shoots antioxidant enzymes activities in several plant species grown under toxic levels of metals (Sharma and Dubey, 2007). In the present study, application of Arg, significantly decreased the amount of $\mathrm{H}_{2} \mathrm{O}_{2}$ and LOX activity (Figure 1) which is very important for stress tolerance. In this investigation $\mathrm{Ni}$ toxicity stimulates the production of proline which is anti-an oxidative metabolite. Arg pre-treatment had no significant effects on the amount of this compound and even in some cases Arg pre-treatment decreased the amount of proline in control and stressed plants (Figure 2). It appears that the Arg pre-treatment induced the PAs pathways and so proline content decreased significantly in these plants. Pre-treatment of hyoscyamus plants with Arg Also decreased the activity of CAT, GPX and APX under stress condition when compared with nonpretreated plants (Figure 3 ). 

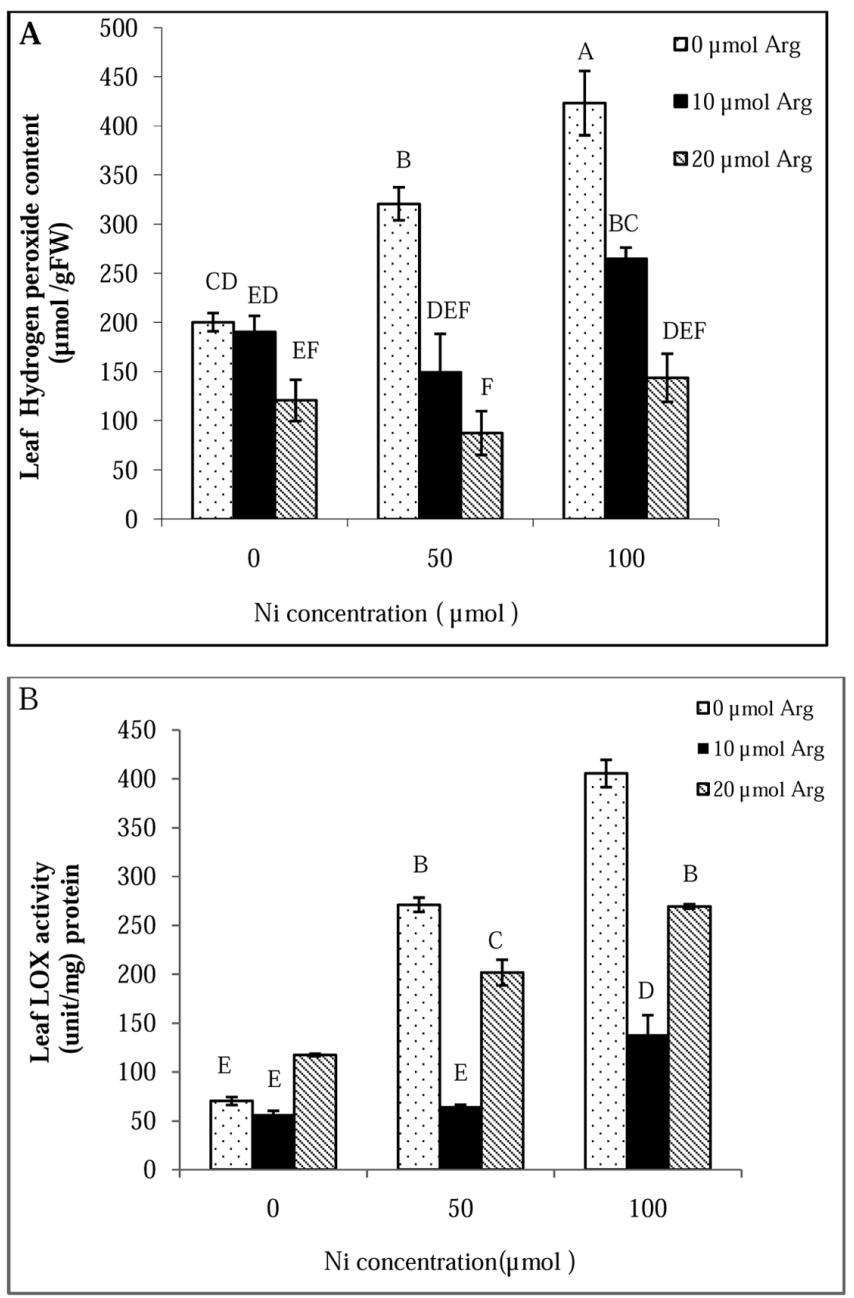

Figure 1. Effect of Arg pre-treatment on $\mathrm{H}_{2} \mathrm{O}_{2}$ content (A) content and LOX activity (B) in hyoscyamus leaves under control and Ni stress condition. Data are means \pm SE of three replicates. The significant of different between treatments was determined by one-way ANOVA taking $p<0.05$ as significant

In previous study, it has been shown that Arg pretreatment decreased the activity of CAT and GPX in tomato plants under drought stress (Nasibi et al., 2011). Arginine is the main amino acid in plants and two main pathways of its metabolism have been reported which are catalyzed by either arginase or nitric oxide synthase so that the endproduct will be ornithine or nitric oxide respectively. Ornithine is a precursor for polyamines or proline biosynthesis (Liu et al., 2006). In previous studies, the effects of nitric oxide, proline and polyamines in the protection of plants against heavy metal stress were reported. For example, oxidative 
stress induced by excessive $\mathrm{Cu}$ was effectively alleviated in tomato plant by application of SNP. Cui et al., (2010) reported that exogenous NO was able to improve shoot height and fresh weight of tomato plants subjected to $\mathrm{Cu}$ stress. By determining the activities of SOD, peroxide dismutase (POD), APX and CAT, they concluded that NO exerted its protective effect through the activation of some antioxidative enzymes, not by preventing $\mathrm{Cu}$ uptake and transport. In other studies, it was reported that the function of $\mathrm{NO}$ alleviation of oxidative damage could well be the induction of various ROS-scavenging enzyme activities (Hsu and Kao, 2004). Wang et al. (2007) reported that exogenous application of spermidine (Spd) and spermine ( $\mathrm{Spm}$ ) prevented lipid peroxidation, reduced the excessive accumulation of $\mathrm{Cu}$, maintained the balance of nutrient elements, and effectively alleviated the toxicity of $\mathrm{Cu}$ in Nymphoides peltatum leaves. Therefore, it seems that in our study protective effects of Arg may be related to polyamines, NO production or proline biosynthesis. In this study, the measurement of $\mathrm{Ni}$ concentration in shoot showed that when plants were pretreated with Arg the concentration of $\mathrm{Ni}$ increased in the shoot. Therefore, it seems that Arg had the chelator role for the translocation of $\mathrm{Ni}$ from root to shoot. In many cases the effects of some amino acids such as histidine, serine, proline and methionine in protection of plants against heavy metal stress has been reported (Shanti et al., 2006). For example Alyssum montanum, when supplied with exogenous histidine, transported more Ni to the shoot as a result of enhanced $\mathrm{Ni}$ flux into the xylem and showed tolerance to applied $\mathrm{Ni}$ concentrations (Kerkeb and Krämer, 2003). The Ni hyper-accumulation trait in Alyssum species (Brassicaceae) has been demonstrated to be specifically linked to the ability for free histidine production (Krämer et al., 1996). Genetically increased capacity for metal-induced Cys synthesis was shown to support survival of Arabidopsis under acute Cd stress (Dominguez-Solis et al., 2004). In this connection, the capability of plant to accumulate stress-induced polyamine is of great interest; polyamines manifest a multifunction defensive role against various abiotic factors, heavy metal in particular (Kuznetsov et al., 2006). Therefore, their properties, such as an easy chelation of heavy metal, Ni in particular (Koutensky et al., 1995), attract the attention of researchers.

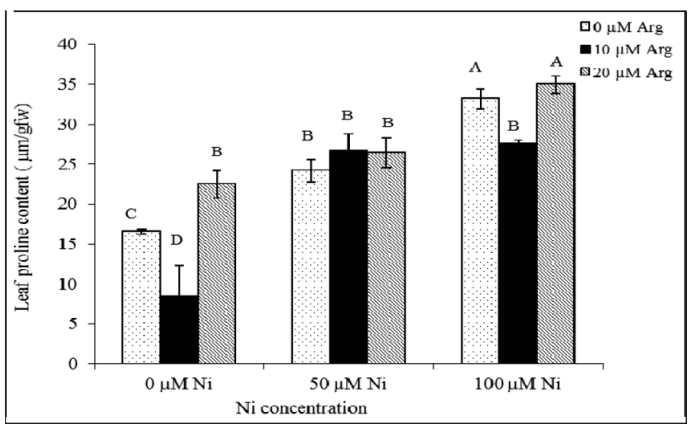

Figure 2. Effect of Arg pre-treatment on proline content in leaves of hyoscyamus under control and $\mathrm{Ni}$ stress condition. The significant of different between treatments was determined by one-way ANOVA taking $p<0.05$ as significant. 

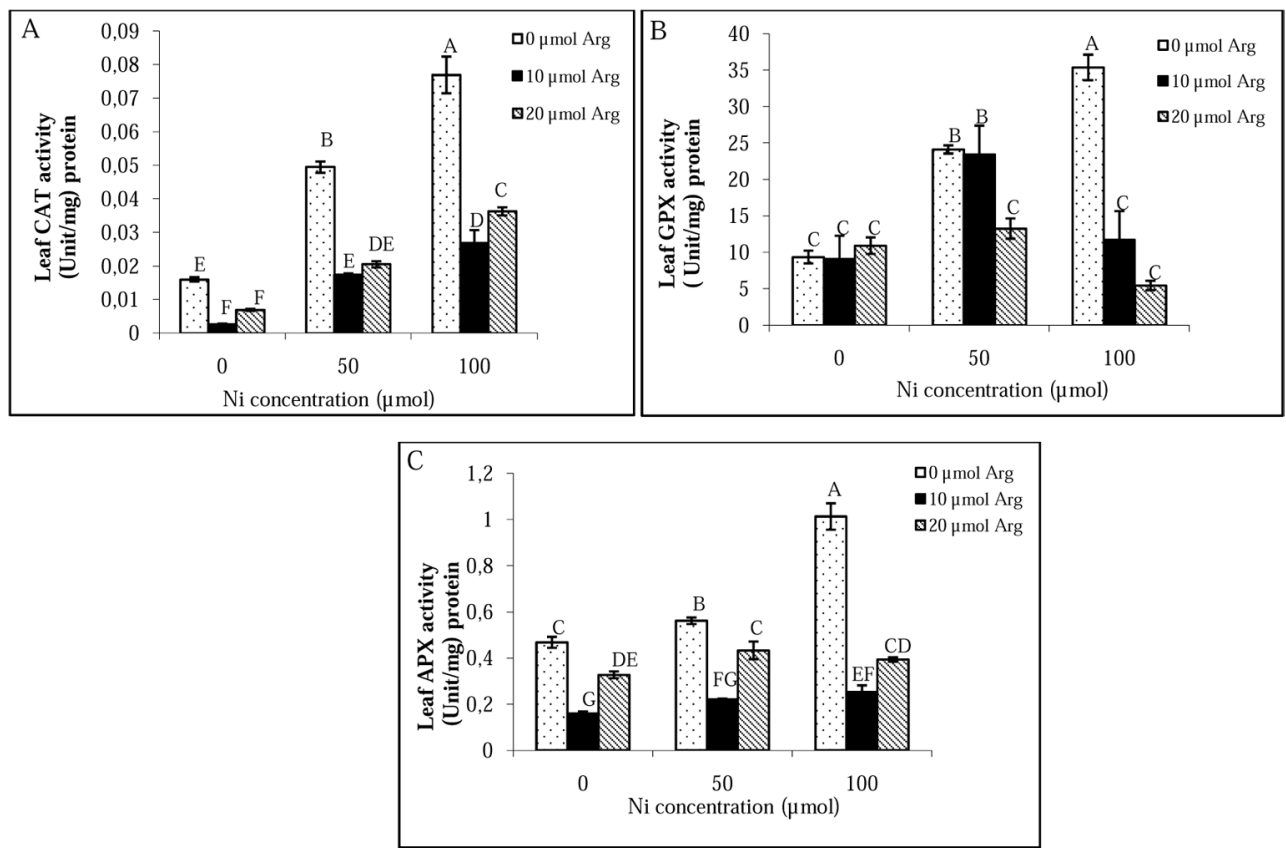

Figure 3. Effect of Arg pre-treatment on CAT (A), GPX (B) and APX (C) activity in tomato plant leaves under control and Ni stress condition. Data are means \pm SE of three replicates. The significant of different between treatments was determined by one-way ANOVA taking $p<0.05$ as significant.

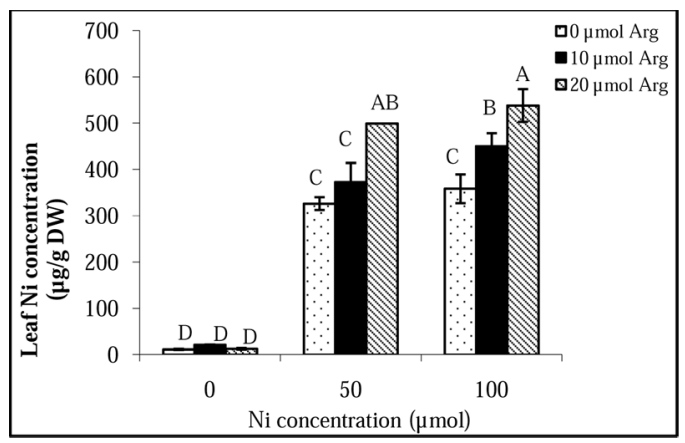

Figure 4. Effect of Arg pre-treatment on Ni content in leaves of hyoscyamus niger under control and Ni stress condition. The significant of different between treatments was determined by one-way ANOVA taking $p<0.05$ as significant. 


\section{Conclusions}

In conclusion it is shown for the first time that pretreatment of hoscyamus plant with Arg increased their capability of $\mathrm{Ni}$ accumulation in aboveground organs by 1.5-2 times and reduced its toxic effects on chlorophyll content and oxidative parameters. It might be that arginine induced weakening Ni toxicity and its accelerated transport in plants (chelation) directly on through production of polyamines or NO.

\section{References}

Alexieva, V., Sergiev, I., Mapelli, S., Karanov, E. 2001. The effect of drought and ultraviolent radiation on growth and stress markers in pea and wheat. Plant Cell Environ. 24, 1337- 1344.

Bates, L.S. 1973. Rapid determination of free proline for water stress studies. Plant Soil. 39, 205-207.

Boominathan, R., Doran, P.M. 2002. Ni-induced oxidative stress in roots of the $\mathrm{Ni}$ hyperaccumulator Alyssum bertolonii. New Phytol. 156, 205-215.

Bradford, M.M. 1976. A rapid and sensitive method for quantitation of microgram quantities of protein utilizing the principle of protein-dye binding. Anal. Biochem. 72, 248-254.

Cui, X.M., Zhang, Y.K., Wu, X.B., Liu, C.S. 2010. The investigation of the alleviated effect of copper toxicity by exogenous nitric oxide in tomato plants. Plant Soil Environ. 56, 274-281.

Doderer A., Kokkelink I., Vanderween S., Valk B., Schrom A.W., Douma A.C. 1992: Purification and characterization of two lipoxygenase isoenzymes from germinating barley. Biochem Biophys Acta. 1120, 97-104.

Dominguez-Solis, J.R., Lopez-Martin, M.C., Ager, M.C., Ynsa, M.D., Romero, L.C., Gotor, C.
2004. Increased cysteine availability is essential for cadmium tolerance and accumulation in Arabidopsis thaliana. Plant Biotech. J. 2, 469-476.

Gajewska, E., Sklodowska, M. 2005. Antioxidative responses and proline level in leaves and roots of pea plants subjected to nickel stress. Acta Physiol. Plant. 27, 329-339.

Hsu, Y.T., Kao, C.H. 2004. Cadmium toxicity is reduced by nitric oxide in rice leaves. Plant Growth Regul. 42, 227-238.

Kerkeb, L., Krämer, U. 2003. The role of free histidine in xylem loading of nickel in Alyssum lesbiacum and Brassica juncea. Plant Physiol. 131, 716-724.

Koutensky, J., Koutenska, M., Kotyzova, D., Eybl, V. 1995. Interaction of nickel and some polyamines in vivo. Toxicol. Lett. 78, 49-50.

Krämer, U., Cotter-Howells, J.D., Charnock, J.M., Baker, A.J.M., Smith, J.A.C. 1996. Free histidine as a metal chelator in plants that accumulate nickel. Nature. 379, 635-638.

Kuznetsov, V., Radyukina, N. L., Shevyakova, N. I. 2006. Polyamines and Stress: Biological Role, Metabolism, and Regulation. Russian J. P. Physiol. 53, 658-683.

Lichtenthaler, H. K. 1987. Chlorophyll and carotenoids: pigments of photosynthetic biomembranes. Method Enzymol. 148, 350-382.

Liu, J.H., Nada, K., Honda, C., Kitashiba, H., Wen, X.P. 2006. Polyamine biosynthesis of apple callus under salt stress. Importance of the arginine decarboxylase pathway in stress responses. J. Exp. Bot. 57, 2589-2599.

Mehta, S.K., Gaur, J.P. 1999. Heavy metal induced proline accumulation and its role in ameliorating metal toxicity in Chlorella vulgaris. New Phytol. 143, 253- 259. 
Mittova, V., Volokit, M., Guy, M., Tal, M. 2000. Activities of SOD and the ascorbate-glutathione cycle enzymes in subcellular compartments in leaves and roots of the cultivated tomato and its wild salt-tolerant relative Lycopersicon pennellii. Physiol. Plant. 110, 45-50.

Nakano, Y., Asada, K. 1981. Hydrogen peroxide is scavenged by ascorbate-specific peroxidase in spinach choloroplast. Plant Cell Physiol. 22, 867880.

Nasibi, F., Kalantari, Kh. 2009. Influence of nitric oxide in protection of tomato seedling against oxidative stress induced by osmotic stress. Acta Physiol. Plant. 31, 1037-1044.

Nasibi, F., Yaghoobi, M.M., Kalantari, Kh. 2011. Effect of exogenous arginine on alleviation of oxidative damage in tomato plant under water stress. J. Plant Interact. 6, 291-296.

Pilon-Smits, E., Pilon-Shevyakova, M. 2002. Phytoremediation of metals using transgenic plants. Crit. Rev. Plant Sci. 21, 439-456.

Plewa, M.J., Smith, S.R., Wanger, E.D. 1991. Diethyldithiocarbamate suppresses the plant activation of aromatic amines into mutagens by inhibiting tobacco cell peroxidase. Mutat. Res. 247, 57-64.

Seregin, I. V., Kozhevnikova, A. D. 2006. Physiological role of nickel and its toxic effects on higher plants. Russ. J. Plant Physiol. 53, 257-277.
Shanti, S., Sharma, S., Dietz, K.J. 2006. The significance of amino acids and amino acid-derived molecules in plant responses and adaptation to heavy metal stress. J. Exp. Bot. 57 (4), 711-726.

Sharma, P., Dubey, R.S. 2007. Involvement of oxidative stress and role of antioxidative defense system in growing rice seedlings exposed to toxic concentrations of aluminum. Plant Cell Rep. 26, 2027-2038

Shi, Q., Ding, F., Wang, X., Wei, M. 2007. Exogenous nitric oxide protects cucumber roots against oxidative stress induced by salt stress. Plant Physiol. Biochem. 45, 542-550

Tewari, R. K., Hahn, E. J., Paek, K. Y. 2008. Modulation of copper toxicity-induced oxidative damage by nitric oxide supply in the adventitious roots of Panax ginseng. Plant Cell Reports. 27, 171-181.

Velikova, V., Yordanov, I., Edreva, A. 2000. Oxidative stress and some antioxidant systems in acid raintreated bean plants. Protective role of exogenous polyamines. Plant Sci. 151, 59-66.

Wang, X., Shi, A., Xu, Q., Hu, J. 2007. Exogenous polyamines enhance copper tolerance of Nymphoides peltatum. J. Plant Physiol. 164, 1062-1070.

Yang, X. 1996. Plant tolerance to nickel nutrients toxicity. Nickel effects on influx and transport of mineral nutrients in four plant species. J. Plant Nutr. 19, 265-279. 